\title{
Increase in reptile-associated human salmonellosis and shift toward adulthood in the age groups at risk, the Netherlands, 1985 to 2014
}

L Mughini-Gras ${ }^{1}$, M Heck $^{1}$, W van Pelt ${ }^{1}$

1. National Institute for Public Health and the Environment (RIVM), Centre for Infectious Disease Control, Bilthoven, the Netherlands

Correspondence: Lapo Mughini-Gras (lapo.mughini.gras@rivm.nl)

Citation style for this article:

Mughini-Gras L, Heck M, van Pelt W. Increase in reptile-associated human salmonellosis and shift toward adulthood in the age groups at risk, the Netherlands, 1985 to 2014. Euro Surveill. 2016;21(34):pii=30324. DOI: http://dx.doi.org/10.2807/1560-7917.ES.2016.21.34.30324

While the contribution of the main food-related sources to human salmonellosis is well documented, knowledge on the contribution of reptiles is limited. We quantified and examined trends in reptile-associated salmonellosis in the Netherlands during a 30-year period, from 1985 to 2014 . Using source attribution analysis, we estimated that $2 \%$ ( $95 \%$ confidence interval: $1.3-2.8)$ of all sporadic/domestic human salmonellosis cases reported in the Netherlands during the study period $(n=63,718)$ originated from reptiles. The estimated annual fraction of reptile-associated salmonellosis cases ranged from a minimum of $0.3 \%$ (corresponding to 11 cases) in 1988 to a maximum of $9.3 \%$ (93 cases) in 2013. There was a significant increasing trend in reptile-associated salmonellosis cases (+19\% annually) and a shift towards adulthood in the age groups at highest risk, while the proportion of reptile-associated salmonellosis cases among those up to four years-old decreased by $4 \%$ annually and the proportion of cases aged 45 to 74 years increased by $20 \%$ annually. We hypothesise that these findings may be the effect of the increased number and variety of reptiles that are kept as pets, calling for further attention to the issue of safe reptile-human interaction and for reinforced hygiene recommendations for reptile owners.

\section{Introduction}

Salmonella is a natural inhabitant of the reptile gut microflora, detected in ca $50 \%$ of reptile pets [1]. As pet reptiles have become increasingly popular, so have reptile-associated Salmonella infections in humans [2]. Most Salmonella isolates from reptiles belong to the Salmonella enterica subspecies II (salamae), IIla (arizonae), IIIb (diarizonae), VI (houtenae), and a few to S. bongori (formerly subspecies V) and VI (indica). However, also the subspecies I (enterica), mainly associated with warm-blooded organisms, is often found in reptiles [3], as it can be present in the reptiles' meals (e.g. rodents, birds or raw vegetables). Accordingly, exposure to reptiles is associated with a four- and twofold increased risk for infection with typical and atypical reptile-associated Salmonella, respectively [2]. Moreover, reptile-associated salmonellosis mainly affects young children and results in a higher incidence of hospitalisation and invasive disease than other Salmonella infections [2].

The contribution of the main food-related sources to human salmonellosis is well documented [4-7]. In contrast, the knowledge on the contribution of reptiles is limited [3]. In order to address this knowledge gap, we quantified and examined trends in reptile-associated salmonellosis in the Netherlands during a 30-year period from 1985 to 2014 .

\section{Methods}

We performed source attribution of human salmonellosis cases using the modified Dutch model, which has been presented in detail previously $[4,5,8]$. Briefly, the model infers probabilistically the most likely sources of human cases by comparing their Salmonella subtype distribution with that of the sources, weighted by the Salmonella prevalence in these sources and the human exposure to them, i.e. the per capita food consumption and likelihood of consuming raw/undercooked food or the per capita ownership of reptiles in the general population. Model parameters are summarised in Table 1.

We used national surveillance data for all 73,124 laboratory-confirmed human salmonellosis cases reported in the Netherlands during the period from January 1985 to December 2014. Non-typhoid salmonellosis is not a notifiable disease in the Netherlands. However, a national passive surveillance system for Salmonella has been in place since 1984 , with an estimated $62 \%$ coverage of the general population based on a network of diagnostic laboratories that submit Salmonella isolates (with accompanying metadata) to the RIVM for further typing [9]. 
Serotyping of all these isolates and further phage typing of the $S$. Enteritidis and $S$. Typhimurium isolates was performed by the national reference laboratory for Salmonella at the Dutch National Institute for Public Health and the Environment (RIVM) as described elsewhere [10]. We also used all available Salmonella isolates from five putative sources, i.e. pigs $(n=14,395)$, cattle $(n=11,189)$, broiler chickens $(n=51,492)$, table eggs/table egg-laying hens $(n=7,412)$ and reptiles $(n=2,281)$ that had been collected during the same period by the Dutch veterinary services (food-producing animals) and private clinics (reptile pets) as part of their routine diagnostic activities and monitoring/surveillance programmes on animals and animal-derived foods at the levels of farm, slaughterhouse and retail (Table 2). Also these isolates were typed at the RIVM within the framework of the national surveillance system for Salmonella using the same methods as for the human isolates.
Of the 73,124 human cases, 5,579 (7.6\%) and 1,683 (2.3\%) were excluded from the source attribution analysis because they were travel- and outbreak-related, respectively. Another 2,144 cases (2.9\%) were excluded because their sero/phage types were not found in any of the considered sources; these cases were then assigned to an unknown source. The model attributed the remaining 63,718 sporadic/domestic cases to the five animal sources. To avoid issues related to sparse data, each year of human cases was attributed based on the subtypes of three years of data for pigs, broilers and layers/eggs (i.e. the same year and the years before and after) and based on all years of reptile data. Interannual trends in the fraction of cases attributed to reptiles were assessed using the Cochran-Armitage test.

\section{Results}

Most reptile isolates (59\%) belonged to S. enterica subspecies other than subspecies I, particularly to

\section{TABLE 1}

Parameters of the modified Dutch model for source attribution

\begin{tabular}{|c|c|c|}
\hline Parameter & Description/estimation & Reference \\
\hline$\lambda_{i j}$ & $\begin{array}{l}\text { Estimated number of human infections caused by subtype } i \text { from source } j \text {, given by } \\
\qquad \frac{p_{i j} \times m_{j} \times c_{j}}{\sum_{j} p_{i j} \times m_{j} \times c_{j}} \times e_{i}\end{array}$ & {$[4,5,8]$} \\
\hline$p_{i j}$ & Prevalence of subtype $i$ from source $j$, given by $\pi j \times r i j$ & {$[1,3,4,16] ;$ this study } \\
\hline$\pi_{j}$ & Overall prevalence of Salmonella spp. in source $j$ & {$[1,3,4,16,17]$} \\
\hline$r_{i j}$ & Relative frequency of serotype $i$ in source $j$ & This study \\
\hline$m_{j}$ & $\begin{array}{l}\text { Amount of source } j \text { per person per year available on the market } \\
\text { (kg for food-animals or number for reptiles) }\end{array}$ & {$[4,18,19]$} \\
\hline$c_{j}$ & $\begin{array}{l}\text { Probability for foods from source } j \text { to be eaten raw/undercooked by the population } \\
\text { (not applicable for reptiles) }\end{array}$ & {$[5,20]$} \\
\hline$e_{i}$ & Frequency of human salmonellosis cases of subtype $i$ & Data \\
\hline
\end{tabular}

\section{TABLE 2}

Salmonella subspecies and serotypes in humans $(n=63,718)$ and animal sources $(n=86,769)$, the Netherlands, 1985-2014

\begin{tabular}{|c|c|c|c|c|c|c|c|c|c|c|c|c|c|}
\hline \multirow{2}{*}{ Subspecies } & \multirow{2}{*}{ Serotype } & \multicolumn{2}{|c|}{ Humans ${ }^{a}$} & \multicolumn{2}{|c|}{ Reptiles } & \multicolumn{2}{|c|}{ Pigs } & \multicolumn{2}{|c|}{ Cattle } & \multicolumn{2}{|c|}{ Layers/eggs } & \multicolumn{2}{|c|}{ Broilers } \\
\hline & & $\mathrm{n}$ & $\%$ & $\mathrm{n}$ & $\%$ & $\mathrm{n}$ & $\%$ & $\mathrm{n}$ & $\%$ & $\mathrm{n}$ & $\%$ & $\mathrm{n}$ & $\%$ \\
\hline \multirow{5}{*}{ S. enterica (I) } & $\begin{array}{l}\text { Typhimurium and its } \\
\text { monophasic variant }\end{array}$ & 27,709 & 43.49 & 63 & 2.76 & 8,984 & 62.41 & 4,620 & 41.29 & 359 & 4.84 & 8,832 & 17.15 \\
\hline & Enteritidis & 18,913 & 29.68 & 22 & 0.96 & 78 & 0.54 & 113 & 1.01 & 3,279 & 44.24 & 5,200 & 10.10 \\
\hline & Typhi & 402 & 0.63 & \multicolumn{2}{|c|}{0} & \multicolumn{2}{|c|}{0} & \multicolumn{2}{|c|}{0} & \multicolumn{2}{|c|}{0} & \multicolumn{2}{|c|}{0} \\
\hline & Paratyphi A/B/C & 487 & 0.76 & 1 & 0.04 & 14 & 0.10 & 4 & 0.04 & 82 & 1.11 & 4,409 & 8.56 \\
\hline & Others & 16,107 & 25.28 & 849 & 37.22 & 5,316 & 36.93 & 6,450 & 57.65 & 3,688 & 49.80 & 33,032 & 64.15 \\
\hline \multicolumn{2}{|l|}{ S. salamae (II) } & 24 & 0.04 & 276 & 12.10 & 1 & 0.01 & \multicolumn{2}{|c|}{0} & 2 & 0.03 & 9 & 0.02 \\
\hline \multicolumn{2}{|c|}{ S. arizonae (IIIa) } & 13 & 0.02 & 194 & 8.51 & \multicolumn{2}{|c|}{0} & \multicolumn{2}{|c|}{0} & 1 & 0.01 & 2 & 0.004 \\
\hline \multicolumn{2}{|c|}{ S. diarizonae (IIIb) } & 41 & 0.06 & 580 & 25.43 & 1 & 0.01 & 2 & 0.02 & 1 & 0.01 & 6 & 0.01 \\
\hline \multicolumn{2}{|c|}{ S. houtenae (IV) } & 21 & 0.03 & 293 & 12.85 & 1 & 0.01 & \multicolumn{2}{|c|}{0} & \multicolumn{2}{|c|}{0} & 2 & 0.004 \\
\hline \multicolumn{2}{|c|}{ S. bongori/indica (V/VI) } & 1 & 0.00 & 3 & 0.13 & \multicolumn{2}{|c|}{0} & \multicolumn{2}{|c|}{0} & \multicolumn{2}{|c|}{0} & \multicolumn{2}{|c|}{0} \\
\hline \multicolumn{2}{|l|}{ Total } & \multicolumn{2}{|c|}{63,718} & \multicolumn{2}{|c|}{2,281} & \multicolumn{2}{|c|}{14,395} & \multicolumn{2}{|c|}{11,189} & \multicolumn{2}{|c|}{7,412} & \multicolumn{2}{|c|}{51,492} \\
\hline
\end{tabular}

a Includes only isolates from sporadic, domestic cases. 
Annual number of reported human salmonellosis cases attributed to different animal sources in the Netherlands, 1985-2014 $(\mathrm{n}=73,124)$

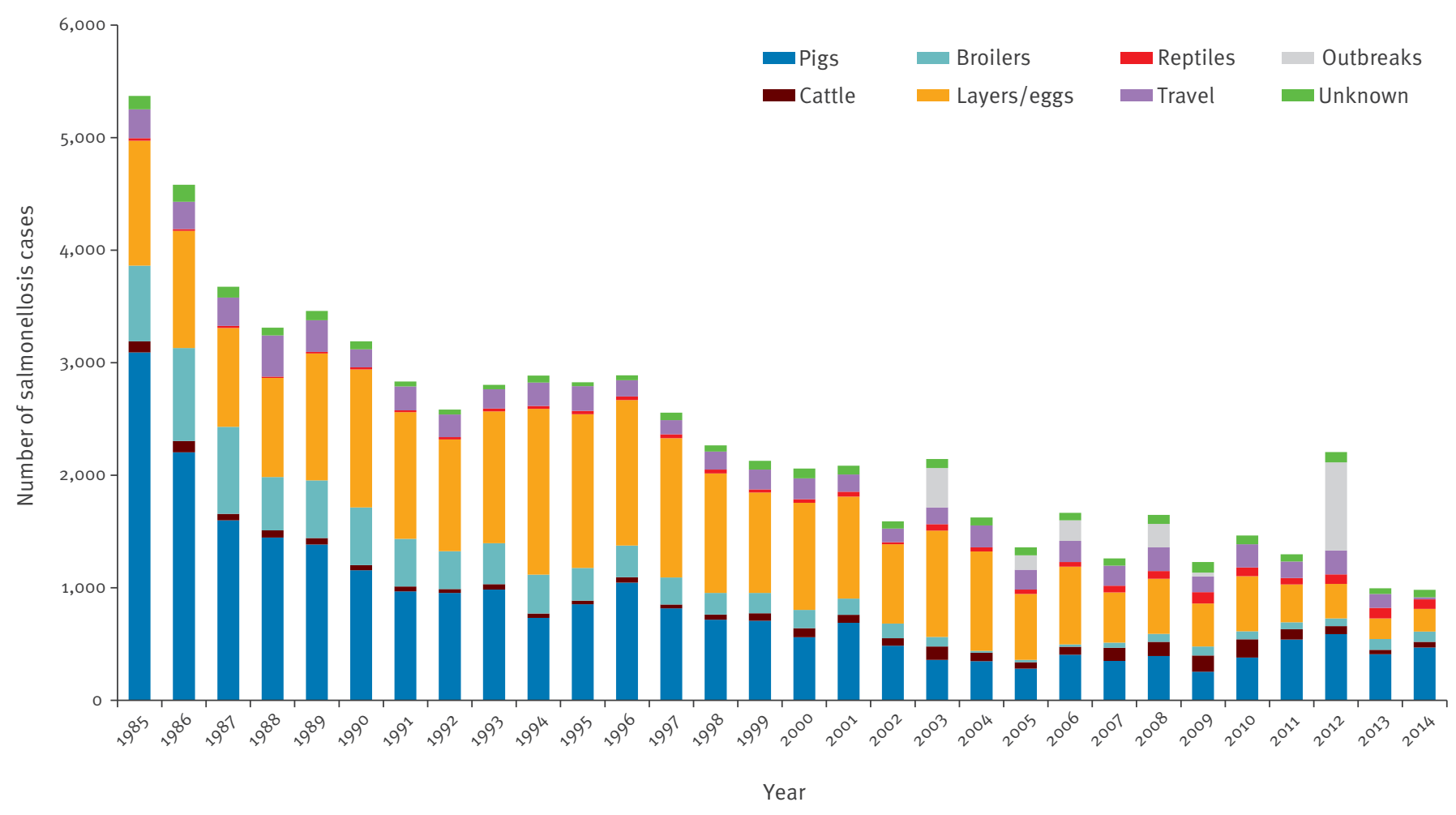

\section{FIGURE 2}

Annual total number of human salmonellosis cases attributed to reptiles, by age group, and estimated fraction of these cases relative to all human salmonellosis cases reported in the Netherlands, $1985-2014(\mathrm{n}=73,124)$

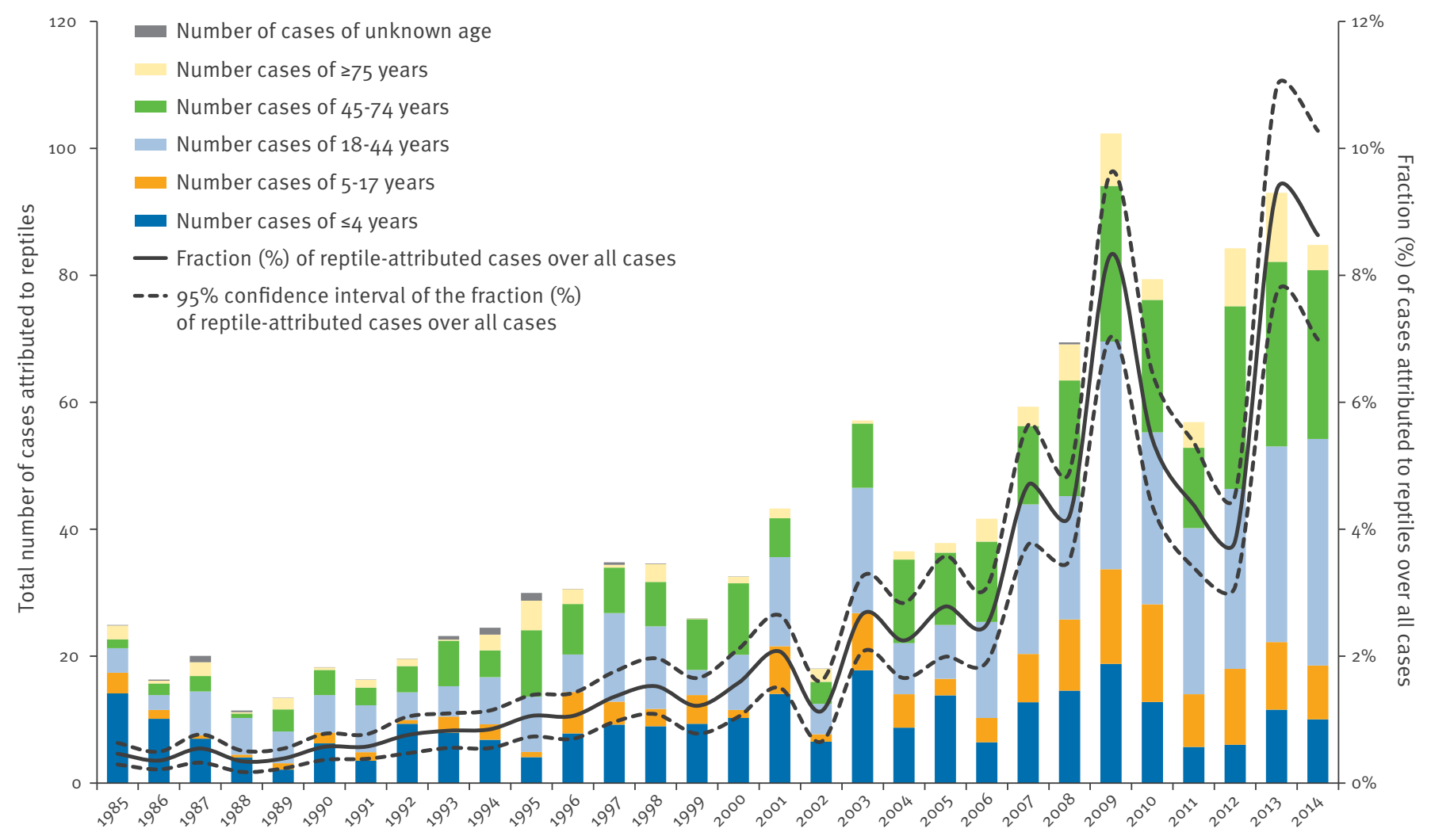

Year 
subspecies IIIb (25\%). In contrast, the vast majority ( $>99 \%)$ of human isolates and isolates from foodproducing animal belonged to subspecies I (Table 2). In total, $2.0 \%$ (95\% confidence interval ( $95 \% \mathrm{Cl}$ ): 1.3-2.8) of human cases were attributed to reptiles; attributions to the other sources were as follows: layers/eggs $41.3 \%$ ( $95 \% \mathrm{Cl}: 36.0-46.5$ ), pigs $40.9 \%$ (95\% Cl: $36.4-45.5)$, broilers $12.3 \%$ (95\% Cl: $10.3-14.4$ ) and cattle $3.5 \%(95 \% \mathrm{Cl}: 2.5-4.5)$. The estimated annual fraction of reptile-associated Salmonella infections ranged from a minimum of $0.3 \%$ (corresponding to 11 cases) in 1988 to a maximum of $9.3 \%$ (93 cases) in 2013 (Figure 1). Although human cases decreased over the years (Figure 1), there was a significant increasing trend $(p<0.0001)$ in the fraction of reptile-associated Salmonella infections $(+19 \%$ on average each year) (Figure 2). Figure 1 also shows the rise and fall of the $S$. Enteritidis epidemic linked to eggs during the $1990 \mathrm{~s}$ and the growing importance of pigs since the early 2000 s (linked to the emergence of $S$. Typhimurium monophasic variant) after a period of evident decline.

Coloured bars, left vertical axis: number of human salmonellosis cases attributed to reptiles; black line, right vertical axis: estimated proportion of human salmonellosis cases attributed to reptiles.

Looking at the age distribution of reptile-associated Salmonella infections over the years (Figure 2), the proportion of cases younger than five years relative to the older age groups decreased significantly by $4 \%$ annually ( $p<0.0001)$, whereas cases in patients aged 45 to 74 years increased by $20 \%(p=0.006)$ each year.

\section{Discussion}

We showed that despite the observed decline in human salmonellosis cases overall, those associated with reptiles are on the rise and increasingly affecting the adult population. This may be explained by the parallel increase in the trade of live (and often wild-caught) reptiles in the European Union (EU). Although the scale of the illegal market is unknown, 5.9-9.8 million reptiles were (legally) imported into the EU in 2009 alone, a substantial rise from the 1.6 million imported in 2005 , which coincided with the ban on wild bird imports placed by the EU in 2005 in response to the $\mathrm{H}_{5} \mathrm{~N}_{1}$ highly pathogenic avian influenza epidemic in poultry [11]. This lends weight to the hypothesis that the shortage of imported wild birds may have played a role in moving the EU exotic pet market towards reptiles so that prospective and established customers may increasingly have embraced reptiles as pets. This is also mirrored in our attributions, as reptile-associated salmonellosis increased steeply after 2005 (Figure 2).

The observed shift in the age groups at highest risk for reptile-associated salmonellosis may be related to the type of reptiles that are currently kept for companionship. In the past, reptile pets consisted mainly of freshwater aquatic baby turtles like the red-eared slider (Trachemys scripta elegans), a popular childhood pet and an important source of salmonellosis for children. As an example, in the United States (US) in the early seventies, pet turtles were responsible for ca $18 \%$ of salmonellosis cases among children aged one to nine years [12]. This led to a federal ban in 1975 on the sale of turtles with a shell length less than $10 \mathrm{~cm}$, resulting in a $77 \%$ decrease in reptile-associated salmonellosis among children of that age [12]. Although baby turtles have become less popular in the Netherlands since the EU ban on imports of red-eared sliders in 1997 for ethical and environmental reasons, a wider variety of reptile species is currently available on the pet market, and most of these species (mainly lizards and snakes) are clearly meant for adult customers rather than children. This is supported by the increased incidence of venomous (pet) snake bites and other injuries in Europe, extremely rare events until the early 2000 s. Further, the importation of these animals has been linked to the changed biodiversity of the European household fauna $[13,14]$. A resurgence of pet reptiles other than baby turtles is also believed to be responsible for the recent trends in reptile-associated salmonellosis in the US [2].

Our estimate of $\mathbf{2 . 0 \%}$ for reptile-associated salmonellosis is in line with previous estimates based on similar source attribution methods [3], but lower than those based on self-reported exposure to reptiles. For instance, in Sweden, 6\% of all salmonellosis cases from 1998 to 2000 reported exposure to reptiles [15]. In the US, the population attributable fraction for reptile/ amphibian contact was $6 \%$ for all sporadic cases from 1996 to 1997 , and $11 \%$ among those younger than 21 years [2].

\section{Conclusions}

In summary, while human salmonellosis has been decreasing since the 1980 s in the Netherlands, we report an increasing trend in reptile-associated salmonellosis and a shift towards adulthood in the age groups at risk, a possible reflection of the increased number and variety of reptiles that are nowadays kept as pets. Although human salmonellosis remains primarily a food-borne disease and the contribution of reptiles is small, our findings call for further attention to the issue of safe reptile ownership in order to target and reinforce current standing recommendations.

Conflict of interest

None declared.

Authors' contributions

LMG and WvP conceived and designed the study. MH produced the laboratory data. LMG performed the statistical analyses and drafted the manuscript. All authors have substantially contributed to critically reviewing the manuscript and approved it as submitted. 


\section{References}

1. Geue L, Löschner U. Salmonella enterica in reptiles of German and Austrian origin.Vet Microbiol. 2002;84(1-2):79-91. DOI: 10.1016/S0378-1135(01)00437-0 PMID: 11731161

2. Mermin J, Hutwagner L, Vugia D, Shallow S, Daily P, Bender J, et al. Reptiles, amphibians, and human Salmonella infection: a population-based, case-control study. Clin Infect Dis. 2004;38(s3) Suppl 3;S253-61. DOI: 10.1086/381594 PMID: 15095197

3. Bertrand S, Rimhanen-Finne R, Weill FX, Rabsch W, Thornton L, Perevoscikovs J, et al. Salmonella infections associated with reptiles: the current situation in Europe. Euro Surveill. 2008;13(24):18902.PMID: 18761944

4. Mughini-Gras L, Smid J, Enserink R, Franz E, Schouls L, Heck $M$, et al. Tracing the sources of human salmonellosis: a multi-model comparison of phenotyping and genotyping methods. Infect Genet Evol. 2014;28:251-60. DOI: 10.1016/j. meegid.2014.10.003 PMID: 25315490

5. Mughini-Gras L, Enserink R, Friesema I, Heck M, van Duynhoven Y, van Pelt W. Risk factors for human salmonellosis originating from pigs, cattle, broiler chickens and egg laying hens: a combined case-control and source attribution analysis.PLoS One. 2014;9(2):e87933. DOI: 10.1371/journal. pone.0087933 PMID: 24503703

6. Mughini-Gras L, Barrucci F, Smid JH, Graziani C, Luzzi I, Ricci $A$, et al. Attribution of human Salmonella infections to animal and food sources in Italy (2002-2010): adaptations of the Dutch and modified Hald source attribution models. Epidemiol Infect. 2014;142(5):1070-82. DOI: 10.1017/S0950268813001829 PMID: 23920400

7. DE Knegt LV, Pires SM, Hald T. Attributing foodborne salmonellosis in humans to animal reservoirs in the European Union using a multi-country stochastic model.Epidemiol Infect. 2015;143(6):1175-86. DOI: 10.1017/S0950268814001903 PMID: 25083551

8. Mughini-Gras L, van Pelt W. Salmonella source attribution based on microbial subtyping: does including data on food consumption matter?Int J Food Microbiol. 2014;191:109-15. DOI: 10.1016/j.ijfoodmicro.2014.09.010 PMID: 25261828

9. van Pelt W, de Wit MA, Wannet WJ, Ligtvoet EJ, Widdowson MA, van Duynhoven YT. Laboratory surveillance of bacterial gastroenteric pathogens in The Netherlands, 1991-2001. Epidemiol Infect. 2003;130(3):431-41.PMID: 12825727

10. van Duijkeren E, Wannet WJ, Houwers DJ, van Pelt W. Serotype and phage type distribution of salmonella strains isolated from humans, cattle, pigs, and chickens in the Netherlands from 1984 to 2001.J Clin Microbiol. 2002;40(11):3980-5. DOI: 10.1128/JCM.40.11.3980-3985.2002 PMID: 12409362

11. Wild Pets in the European Union. Horsham: ENDCAP 2012. Available from: http://endcap.eu/wp-content/ uploads/2013/02/Report-Wild-Pets-in-the-European-Union.pdf

12. Cohen ML, Potter M, Pollard R, Feldman RA. Turtle-associated salmonellosis in the United States. Effect of Public Health Action, 1970 to 1976.JAMA. 1980;243(12):1247-9. DOI: 10.1001/ jama.1980.03300380027016 PMID: 7359680

13. Schaper A, de Haro L, Desel H, Ebbecke M, Langer C. Rattlesnake bites in Europe--experiences from southeastern France and northern Germany.J Toxicol Clin Toxicol. 2004;42(5):635-41. DOI: 10.1081/CLT-200026962 PMID: 15462156

14. Warwick C, Steedman C. Injuries, envenomations and stings from exotic pets.J R Soc Med. 2012;105(7):296-9. DOI: 10.1258/ jrsm.2012.110295 PMID: 22843648

15. de Jong B, Andersson Y, Ekdahl K. Effect of regulation and education on reptile-associated salmonellosis.Emerg Infect Dis. 2005;11(3):398-403. DOI: 10.3201/eid1103.040694 PMID: 15757554

16. European Food Safety Authority (EFSA). Biological hazards reports. National zoonoses country reports. C2004-14. Parma: EFSA. [Acccessed: 29 Feb 2016]. Available from: http://www. efsa.europa.eu/en/zoonosesscdocs/zoonosescomsumrep

17. Bouwknegt M, Dam-Deisz W, Wannet WJB, van Pelt W, Visser $G$, van de Giessen AW. Surveillance of zoonotic bacteria in farm animals in The Netherlands - Results from January 1998 until December 2002. Bilthoven, The Netherlands: Rijksinstituut voor Volksgezondheid en Milieu (RIVM). 2004. Available from: http://rivm.openrepository.com/rivm/ bitstream/10029/8900/1/330050001.pdf

18. Feiten and cijfers - Gezelschapsdierensector 2011 [Facts and figures - Fodder Industry]. Den Haag: Hogeschool HAS Den Bosch, 2012. Dutch. Available from: https://issuu.com/hasdenboschinternational/docs/ feiten_cijfers_van_de_gezelschapsdierensector_20

19. Convention on International Trade in Endangered Species of Wild Fauna and Flora (CITES). c1984-14. CITES trade database.
Geneva: CITES. [Accessed: 29 Feb 2016]. Available from: http:// trade.cites.org/

20. Friesema IH, van Gageldonk-Lafeber AB, van Pelt W. Extension of traditional infectious disease surveillance with a repeated population survey.Eur J Public Health. 2015;25(1):130-4. DOI: 10.1093/eurpub/cku122 PMID: 25085476

\section{License and copyright}

This is an open-access article distributed under the terms of the Creative Commons Attribution (CC BY 4.0) Licence. You may share and adapt the material, but must give appropriate credit to the source, provide a link to the licence, and indicate if changes were made.

This article is copyright of the authors, 2016. 